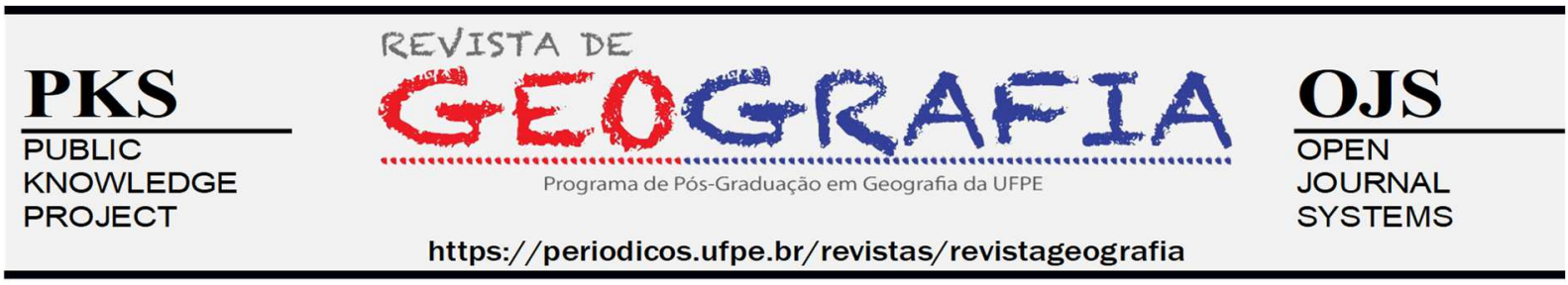

\title{
ALTERAÇÕES NO CICLO HIDROLÓGICO LOCAL - ESTUDO DE CASO: AVENIDA SALDANHA MARINHO, PELOTAS, RS
}

\author{
Liara Kurtz $^{1}$, Andréa Souza Castro², Diuliana Leandro ${ }^{3}$
}

\begin{abstract}
1 Engenheira Hídrica, Universidade Federal de Pelotas, Pelotas/RS. E-mail: liara.kurtz@gmail.com; http://orcid.org/0000-0003-4751-276X

2 Dra. Recursos Hídricos e Saneamento Ambiental, Universidade Federal do Rio Grande do Sul. Professora e Pesquisadora na Universidade Federal do Pelotas, Pelotas/RS. E-mail: andreascastro@gmail.com; http://orcid.org/0000-0003-1989-684X

${ }^{3}$ Dra. em Ciências Geodésicas, Universidade Federal do Paraná. Professora e Pesquisadora na Universidade Federal do Pelotas, Pelotas/RS. E-mail: diuliana_1@ hotmail.com; http://orcid.org/0000-0002-8092-5550
\end{abstract}

Artigo recebido em 08/06/2020 e aceito em 01/06/2021

\begin{abstract}
RESUMO
A maioria das cidades desenvolveu-se em torno de corpos d'água. Em Pelotas, a população cresceu ao redor do arroio Pelotas e do canal São Gonçalo e se expandiu em direção ao arroio Santa Bárbara, depredando suas margens e impermeabilizando o solo local. Para sanar o problema, o arroio foi desviado para fora da área urbana e seu antigo leito, aterrado. Mas, atualmente, a região da Av. Saldanha Marinho, onde passava o antigo leito, sofre alagamentos, cujos motivos foram estudados neste trabalho, por meio de análise hidrológica da área contribuinte ao local. Os resultados evidenciaram altitudes próximas do nível médio do mar, solos mal drenados e uma grande parte da superfície impermeabilizada na região, dificultando a infiltração das águas pluviais. Como solução, sugeriu-se instalar um dispositivo de drenagem na localidade, para este fim, foram reunidas algumas características hidrológicas da área contribuinte à seção de interesse, possibilitando posterior estudo de viabilidade hidrológica e hidráulica do empreendimento. Outras soluções, como as medidas de controle na fonte, também podem ser implantadas, reduzindo alagamentos em Pelotas e em outras cidades, tornando os ambientes mais saudáveis e com maior qualidade de vida à população.
\end{abstract}

Palavras-chave: alagamentos; drenagem; Arroio Santa Bárbara.

\section{CHANGES IN THE LOCAL HYDROLOGICAL CYCLE - CASE STUDY: AVENIDA SALDANHA MARINHO, PELOTAS, RS}

\begin{abstract}
Most cities developed around water bodies. In Pelotas, the population grew around the Arroio Pelotas and the Canal São Gonçaloand expanded towards the Santa Bárbara stream, depredating its banks, and waterproofing the local soil. To remedy the problem, the stream was diverted out of the urban area and its old bed, grounded. But, currently, the region of Av. Saldanha Marinho, where the old bed used to pass, suffers floods, the reasons for which were studied in this work, through hydrological analysis of the area contributing to the place. The results showed low levels of altitude in the region, poorly drained soilsand a large part of surface waterproofed, making it difficult for rainwater to infiltrate. As
\end{abstract}


a solution, it was suggested to install a drainage device in the locality, for this purpose, some hydrological characteristics of the contributing area to the section of interest were gathered, making possible the subsequent performance of a feasibility study hydrological and hydraulic of theconstruction. Other solutions, such as control measures at the source, can also be implemented, reducing flooding in Pelotas and other cities, making the environments healthier and with a better quality of life for the population.

Keywords: floods; drainage; Arroio Santa Bárbara.

\section{INTRODUÇÃO}

Tanto no Brasil como em outros países, o aumento das áreas urbanizadas e, consequentemente, impermeabilizadas, ocorreu a partir das zonas mais baixas, próximas às várzeas dos rios ou à beira-mar, em direção às colinas e morros, em face da necessária interação da população com os corpos hídricos, utilizados como fonte de alimento e dessedentação, além da via de transporte (CANHOLI, 2005).

Em Pelotas não foi diferente, a cidade desenvolveu-se a partir da primeira charqueada, em 1780, às margens do arroio Pelotas. Em função do progresso comercial devido à favorável posição geográfica em relação à fronteira uruguaia, houve a instalação de demais charqueadas ao longo da margem esquerda do canal São Gonçalo. Ao decorrer do tempo, desencadeou-se um adensamento populacional na região, de forma irregular e sem planejamento, resultando em uma interferência no ciclo hidrológico local, por efeito da impermeabilização do solo, e da ocupação às margens dos cursos d'água (HANSMANN, 2013).

Entretanto, ao longo do século XIX a urbanização começou a se expandir em direção ao arroio Santa Bárbara e em 1921 este já estava envolvido pela malha urbana. Sendo assim, o aumento das edificações e a pavimentação de ruas e avenidas, suprimiram a vegetação e o ambiente natural e aumentaram a parcela do fluxo de escoamento superficial, devido à semi ou total impermeabilização do solo, agravando a ocorrência de inundações que passaram a ocorrer nos arredores das várzeas da cidade. A mesma autora afirma que na primeira metade do século $\mathrm{XX}$, as indústrias começaram a realizar suas instalações ao longo das margens do arroio Santa Bárbara e seus funcionários, a fim de residir próximo ao local de trabalho, também construíram casas na região. Devido a estes fatores, o arroio foi assoreado e poluído, desencadeando uma série de transtornos para a cidade. Então, houve a necessidade de tomar medidas para resolver estes problemas (PETER, 2004; SOARES, 2002). 
A partir de 1950, a Prefeitura de Pelotas, através do extinto Departamento Nacional de Obras e Saneamento iniciou um projeto de cinco importantes obras: a construção da Barragem Santa Bárbara, do Canal Santa Bárbara, dois diques em terra, aterramento do antigo leito do arroio Santa Bárbara, construção de galerias pluviais no local do antigo leito e mais tarde a construção da casa de bombas do canal do Pepino (HANSMANN, 2013). A obra da barragem do arroio Santa Bárbara foi implantada para captação de água potável e regularização das cheias, e o trecho que cruzava a área urbana foi aterrado e o arroio, canalizado e desviado para fora da mesma (OLIVEIRA, 2017).

No entanto, estas obras não sanaram os problemas de drenagem, pois na década de 1970, persistiram os alagamentos, principalmente na localidade da Avenida Saldanha Marinho (centro), situada no antigo leito do arroio Santa Bárbara, a qual apresentou maior frequência de inundação (42\%), entre os anos de 1941 e 2009 (HANSMANN, 2013).

Atualmente, o sistema de drenagem urbana de Pelotas é composto por macro e microdrenagem, esta última é composta por sarjetas, bocas de lobo e galerias menores, enquanto que a macrodrenagem é composta por rios, canais e grandes galerias, que se dirigem para oito estações elevatórias, de onde a água da chuva é bombeada para o Canal São Gonçalo (HANSMANN, 2013). Porém, muitos problemas urbanos em relação ao escoamento superficial não foram sanados, há constantes transtornos com inundações, principalmente na localidade da Avenida Saldanha Marinho. Sendo assim, propõe-se, neste trabalho, compreender o motivo dos alagamentos nesta localidade, através da análise da área hidrológica contribuinte para o local. Além disso, sugerir a implantação de um dispositivo de drenagem e fornecer as características necessárias para o seu dimensionamento hidrológico.

\section{MATERIAIS E MÉTODOS}

\section{Caracterização da área de estudo}

O município de Pelotas localiza-se no sul do estado do Rio Grande do Sul, Brasil, entre as latitudes $31^{\circ} 19^{\prime} 19,9^{\prime \prime}$ e $31^{\circ} 48^{\prime} 2,4^{\prime \prime}$ ' Sul e as longitudes $52^{\circ} 36^{\prime} 43,8^{\prime \prime}$ e $52^{\circ} 00^{\prime} 35,0^{\prime \prime}$ Oeste no sistema de referência geodésico SIRGAS 2000. A bacia hidrográfica do arroio Santa Bárbara (BHASB) está localizada na porção sudoeste do município (Figura 1), estando sua parte superior situada no distrito de Monte Bonito. A BHASB é responsável pela maior parte 
do abastecimento do município de Pelotas devido à construção da barragem Santa Bárbara em 1965, a qual apresenta 352 hectares de área inundada. A região possui clima subtropical úmido, a precipitação média anual de Pelotas é de 1366,9 mm, com temperatura média de $17,6^{\circ} \mathrm{C}$. As condições de relevo variam significativamente, conforme o tipo de solo, podendo ser encontradas até cinco regiões distintas no município: zona alta, zona central, de lombadas, de planícies e a zona inundável (HANSMANN, 2013; OLIVEIRA, 2017; PERUZZO, 2017; SANEP, 2008).

Figura 1 - Localização da Bacia Hidrográfica do Arroio Santa Bárbara.

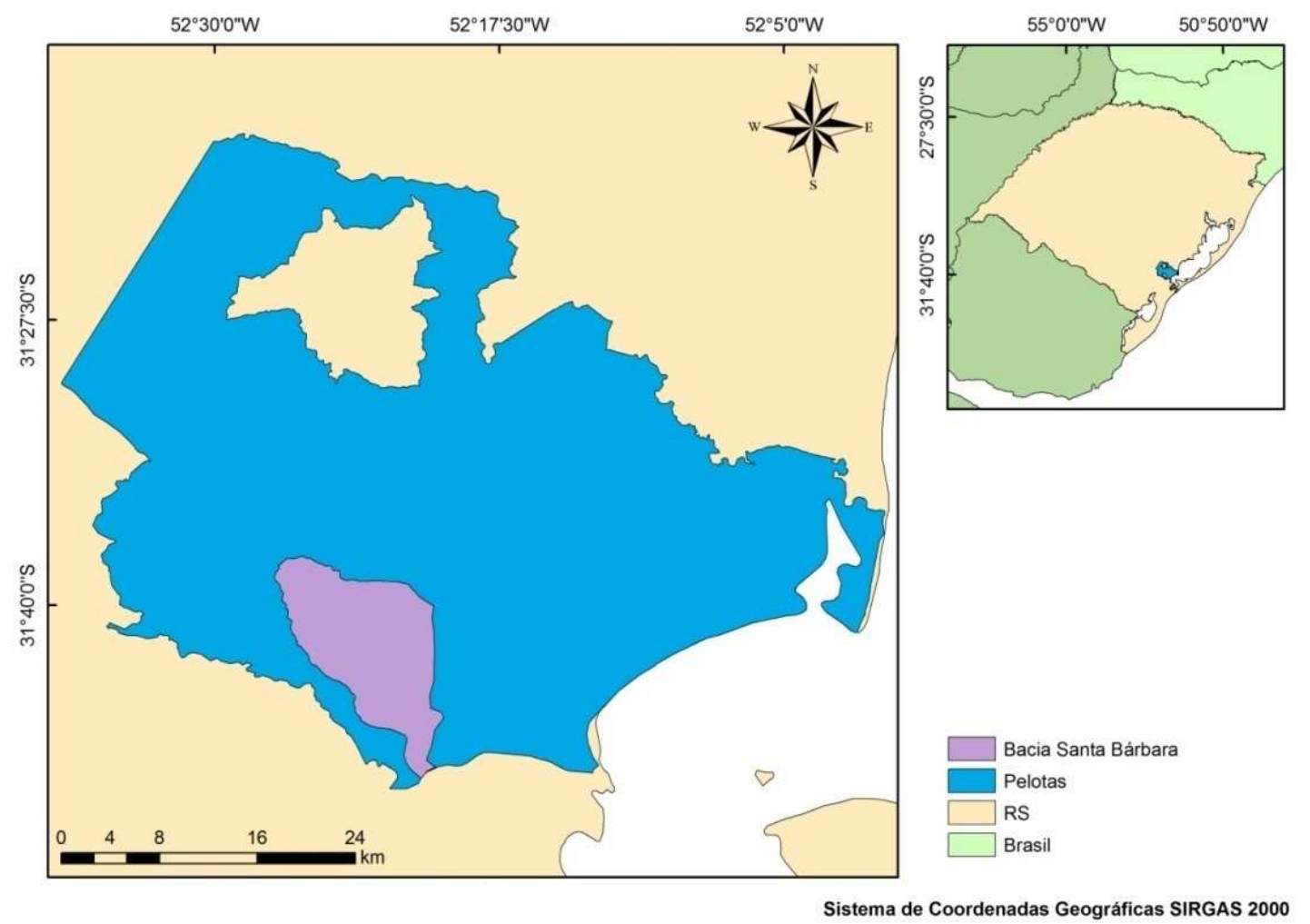

Fontes e tratamento dos dados

Para delimitar a bacia hidrográfica de interesse foi necessário obter o Modelo Digital de Elevação (MDE) da região, elaborado a partir de uma análise multiescala, utilizando imagens SRTM (Shuttle Radar Topography Mission), na escala de 1:250.000, disponíveis no site do TOPODATA, e também, pontos cotados da zona urbana da cidade, fornecidos pelo Serviço Autônomo de Saneamento de Pelotas (SANEP, 2017), na escala 1:2.000. O software utilizado na manipulação destes dados foi o ArcGIS10.2.2, no qual as imagens SRTM da zona 
$31 \mathrm{Sul}$ 52,5 Oeste e 31 Sul 54 Oeste foram associadas ao sistema de referência SIRGAS 2000, alteradas para 16 bits com números inteiros na escala de elevação e, posteriormente, reprojetadas em UTM (Universal Transversa Mercato $^{I}$ ), datum SIRGAS 2000 fuso 22 Sul. Em seguida, receberam o tratamento de suavização das altitudes, a fim de evitar maiores oscilações entre células vizinhas, na tentativa de uma melhor representação do relevo na região. A próxima etapa foi extrair curvas de nível a cada 20 metros, conforme o mapeamento sistemático brasileiro em situações normais para escala 1:50.000 (McCORMAC, 2013).

A partir das curvas de nível e dos pontos cotados na região urbana, foi possível obter o MDE utilizando a ferramenta de triangulação $T_{I N}^{2}$ (Triangulated Irregular Network) do ArcGIS e, por interpolação linear, foi elaborado o MDE no formato matriz (raster: 101,2 m x 101,2 m), preferível para representação de dados contínuos, tais como características naturais e ambientais (McCORMAC, 2013). Por meio destas informações, houve a possibilidade de, posteriormente, delimitar a área de drenagem, cujas etapas estão descritas na sequência. Vale ressaltar que também foi feita uma análise mais detalhada para a região da Avenida Saldanha Marinho, utilizando apenas os dados de pontos cotados do SANEP, na escala 1:1.200, conforme será abordado mais adiante.

Elaborado o MDE (Figura 2), foram aplicadas as ferramentas do ArcHidro para delimitar da área contribuinte de interesse. A primeira etapa foi suavizar as altitudes, a fim de evitar grandes oscilações entre células vizinhas, logo após, aplicou-se ferramentas para, conforme o relevo da região, definir as localidades de acúmulo de fluxo, o que possibilitou observar que toda bacia hidrográfica Santa Bárbara converge para o estacionamento do Pop Center e, em seguida, para Av. Saldanha Marinho, situada à jusante do mesmo (Figura 3).

\footnotetext{
1 O sistema de projeção UTM é o mais utilizado na maioria dos mapas topográficos da USGS (Serviço Geológico dos EUA). Nesse sistema, a Terra é dividida em 60 fusos, cada um com $6^{\circ}$ de largura ao longo do equador, indo de $84^{\circ}$ norte até $80^{\circ}$ sul. Os fusos são numerados de 1 a 60 , começando na longitude $180^{\circ}$ oeste. Os fusos de 18 a 25 cobrem o Brasil, de oeste a leste (McCORMAC, 2013).

2 Este tipo de modelo não proporciona as mesmas facilidades de arrumação da informação que os modelos regulares, embora se adapte à irregularidade das amostras do terreno e permita uma maior fidelidade na representação de linhas de descontinuidade do relevo, tais como cumeeiras e talvegues (CASACA, 2013).
} 
Figura 2 - Modelo Digital de Elevação da BHASB e proximidades, Pelotas, RS.

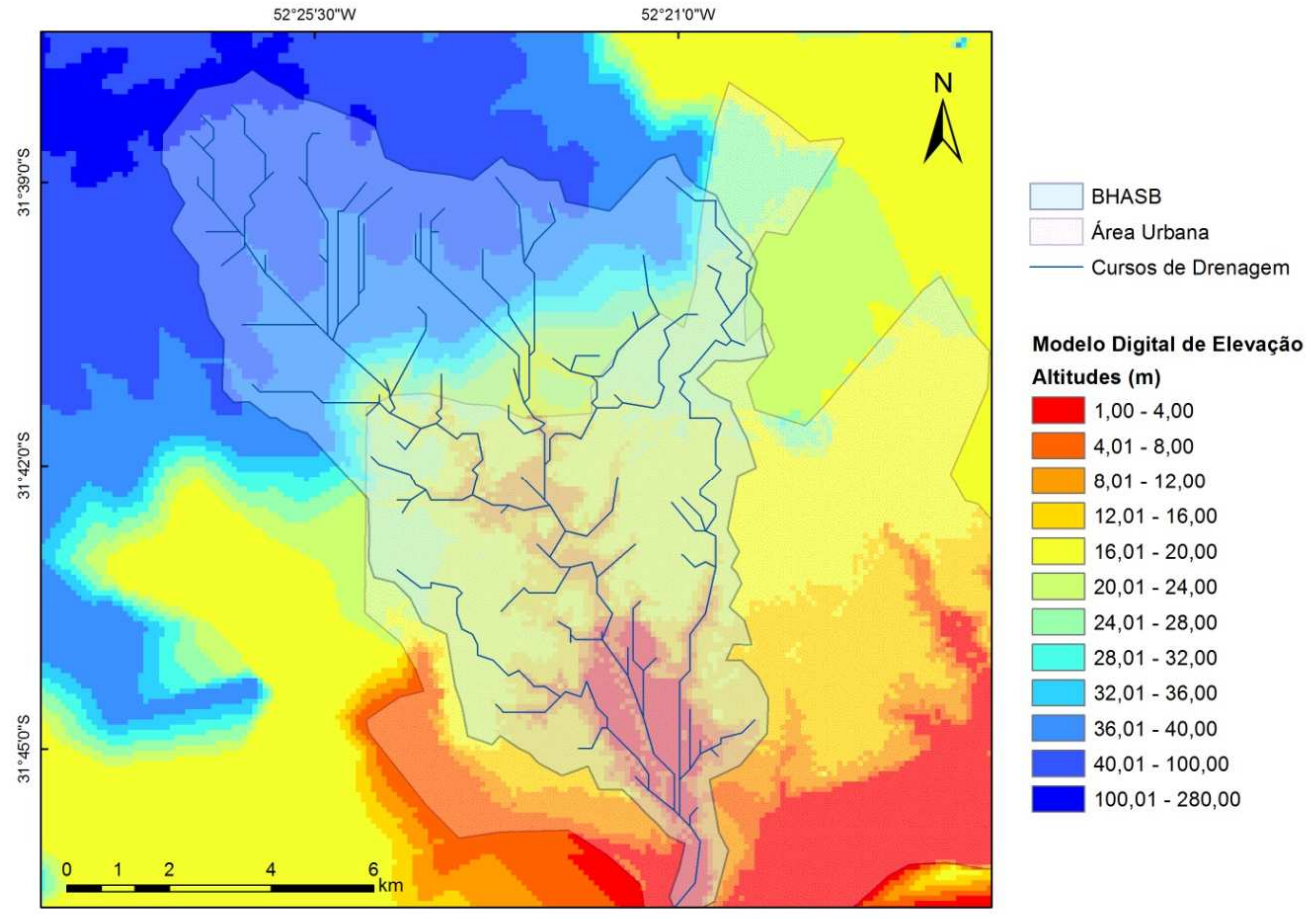

Sistema de Coordenadas Geográficas SIRGAS 2000

Figura 3 - Delimitação da Área Contribuinte para Região da Avenida Saldanha Marinho, Pelotas, RS.
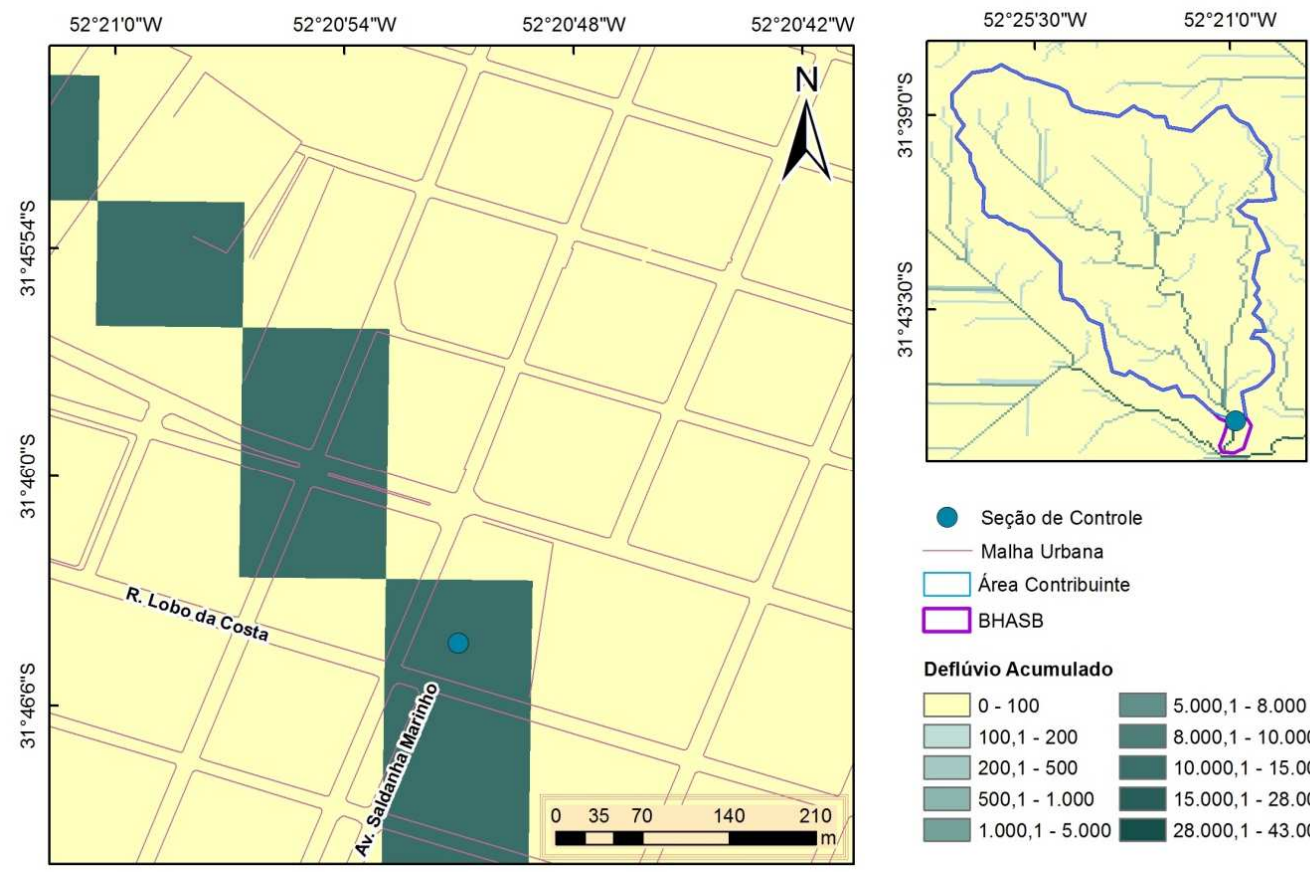

Seção de Controle

Malha Urbana

Área Contribuinte

BHASB

Deflúvio Acumulado

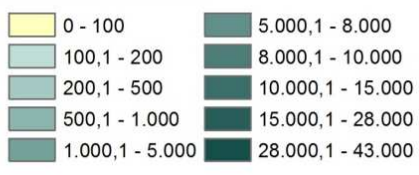

Sistema de Coordenadas Geográficas SIRGAS 2000 
Desta forma, toda a água pluvial à montante da seção de controle no estacionamento, equivalente a grande parte da BHASB, converte para as imediações da Avenida Saldanha Marinho. Um dos prováveis motivos é o fato deste local ser passagem do antigo leito do Arroio Santa Bárbara, algo comprovado em Oliveira (2017), que confirmou a tendência do curso d'água principal da BHASB estar retornando ao seu leito original.

Uma possível solução para os alagamentos na região poderia ser a implantação de um dispositivo de drenagem na avenida, porém, a mesma abriga árvores nativas, sendo assim, esta opção passou a ser inviável do ponto de vista ambiental. Então, uma alternativa poderia ser o estacionamento do Pop Center, situado nas adjacências da avenida.

A geometria do estacionamento do Pop Center foi feita também no software ArcGIS 10.2.2, sua localização foi obtida através dos arruamentos fornecidos também pelo SANEP (dados disponíveis no mesmo arquivo de cotas urbanas), cujo sistema de projeção foi SIRGAS 2000 UTM 22 S. O local de passagem do antigo leito em relação ao estacionamento do Pop Center pode ser visualizado na Figura 4.

Figura 4 - Delimitação do Estacionamento do Pop Center e Trajeto do Antigo Arroio Santa Bárbara.

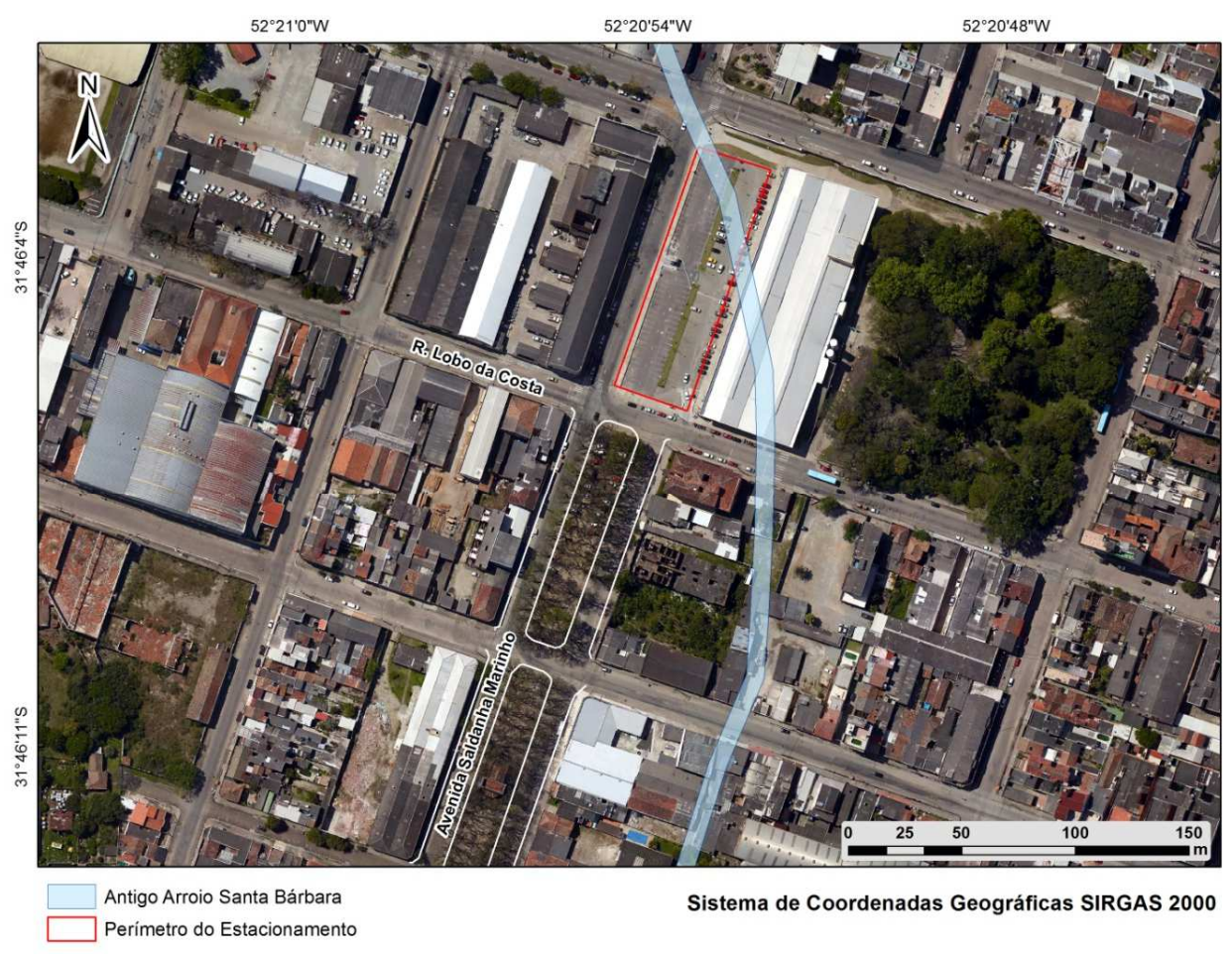


Diante da situação configurada e com o objetivo de delimitar a área contribuinte para a seção de interesse, a opção foi detalhar melhor as condições de deflúvio nas imediações da área de estudo, utilizando, por sua vez, somente os pontos cotados urbanos fornecidos pelo SANEP, em escala 1:2.000. Com base nestes dados, as coordenadas de referência foram novamente projetadas para o sistema SIRGAS 2000 UTM 22 Sul, e na sequência, foi elaborado o Modelo Digital de Elevação da região, por meio da ferramenta Natural Neighbor pertencente ao 3D Analyst Tools, com uma resolução de 2 metros por célula. Em seguida, todas as ferramentas de delimitação da bacia contribuinte ao estacionamento foram idênticas à etapa anterior.

Considerando a contribuição até a seção de controle, a área da BHASB confirmou ser a mesma que converge para as imediações da Avenida Saldanha Marinho, desta vez, utilizando somente os dados de cotas urbanas. A solução, para não condicionar um superdimensionamento de um dispositivo de drenagem, foi estabelecer um limite na área de contribuição. Sendo assim, este limite foi definido em um raio de 550 metros a partir do perímetro do estacionamento, elaborado pela ferramenta buffer e resultando na microbacia urbana de estudo com área igual a 37,5 ha, sua localização em relação à BHASB pode ser visualizada na Figura 5, juntamente com os cursos preferenciais de escoamento superficial (linhas de fluxo) gerados pelas ferramentas do ArcHidro.

A partir da definição dos limites da microbacia de interesse, foram gerados mapas de: linhas de fluxo, cujo talvegue principal foi equivalente à linha de fluxo de maior ordem; altitude, com base nas informações do MDE, e; declividade, por meio da ferramenta Slope do 3D Analyst Tools. 
Figura 5 - Localização da microbacia de estudo em relação à BHASB (contribuição até o estacionamento).

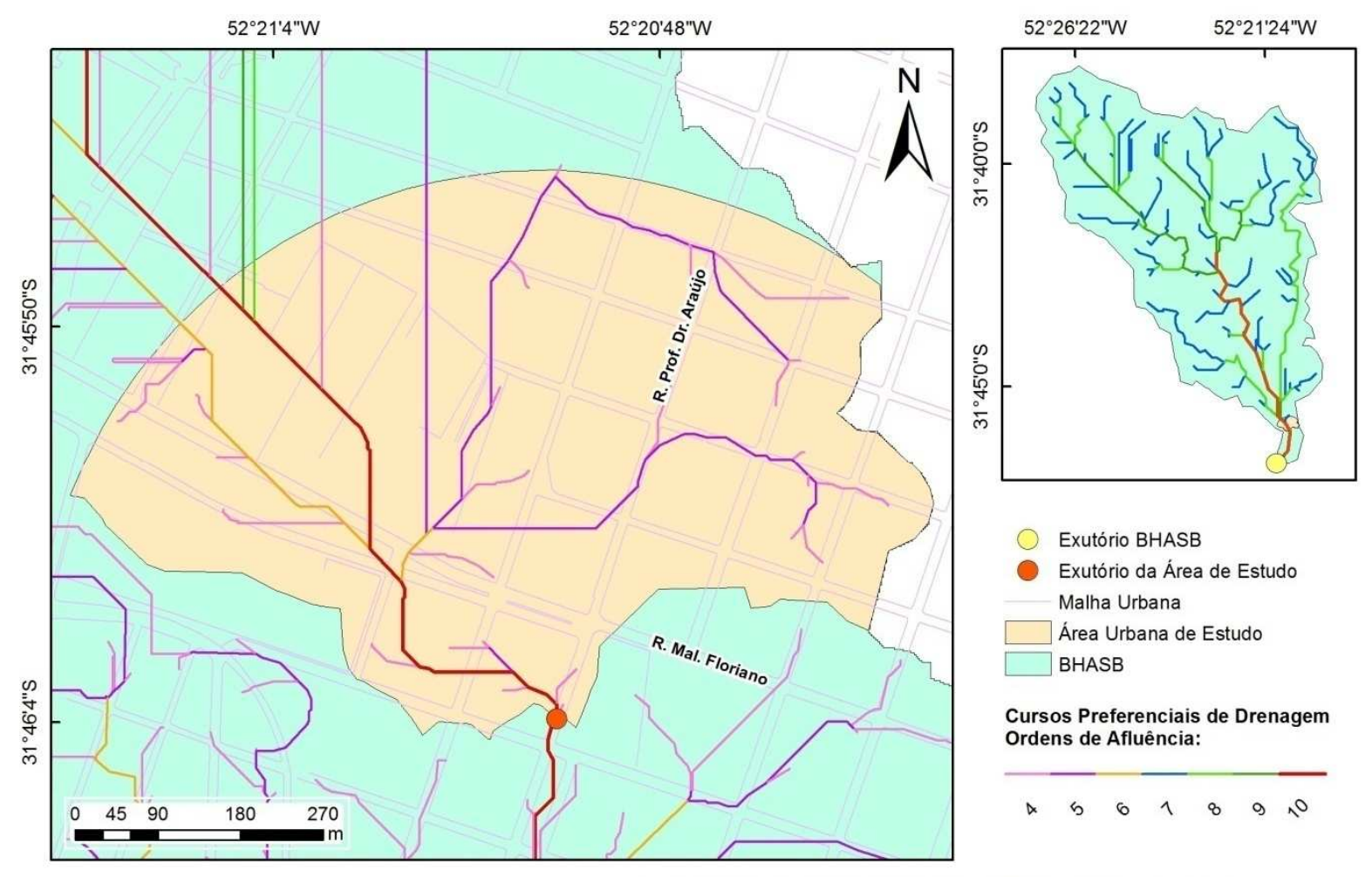

Sistema de Coordenadas Geográficas SIRGAS 2000

Além disso, também foi necessário obter dados a respeito do tipo de solo e do uso e cobertura do solo na microbacia urbana de estudo, para estabelecer suas condições de infiltração, variáveis importantes em um posterior dimensionamento de dispositivo de drenagem.

Os dados utilizados para continuidade do estudo foram: o tipo de solo, dado oriundo da Embrapa, em escala 1:50.000 (CUNHA et al., 2006), e o uso e cobertura do solo, o qual foi determinado através do método de classificação supervisionada no software ArcGIS 10.2.2, a partir de uma ortofoto da zona urbana de Pelotas (PELOTAS, 2015), em escala 1:2.000.

\section{Condições de drenagem}

Para realizar uma análise das características de drenagem na bacia urbana de estudo, foram utilizados dois índices de cobertura e uso do solo, que pertencem a modelos hidrológicos para dimensionamento de dispositivos de drenagem, o índice curve-number $\mathrm{CN}$ 
do método SCS (desenvolvido pelo Soil Conservation Service dos EUA) e o coeficiente de escoamento, ou coeficiente runoff (MIGUEZ et al., 2016).

O índice CN do SCS é um dos mais utilizados, devido a sua capacidade de adequação a diferentes condições, uma das possibilidades é o ajuste conforme quatro tipos diferentes de solo (Tabela 1).

Tabela 1 - Grupos hidrológicos de solos de acordo com o método SCS.

\begin{tabular}{|c|l|}
\hline Grupo A & $\begin{array}{l}\text { Solos arenosos combaixoteor de argila total, inferior a uns } 8 \% \text {, nãohavendo rocha nem camadas } \\
\text { argilosas, e nem mesmo densificadas até a profundidade de 1,5 m. O teor de húmus é } \\
\text { muitobaixo, nãoatingindo } 1 \% \text {. }\end{array}$ \\
\hline Grupo B & $\begin{array}{l}\text { Solos arenosos menos profundos que os do Grupo A e com menor teor de argila total, } \\
\text { porémainda inferior a 15\%. No caso de terrasroxas, esse limite pode subir a 20\% graças à } \\
\text { maiorporosidade. Os doisteores de húmuspodem subir, respectivamente, a 1,2 e 1,5\%. Não pode } \\
\text { haverpedras e nem camadas argilosas até 1,5 m, mas é quasesempre presente camada mais } \\
\text { densificadas que a camada superficial. }\end{array}$ \\
\hline Grupo C & $\begin{array}{l}\text { Solos barrentoscomteor de argila de } 20 \text { a 30\%, massem camadas argilosas } \\
\text { impermeáveisoucontendopedras até profundidades de 1,2 m. No caso de terrasroxas, } \\
\text { essesdoislimites máximos podem ser de 40\% e 1,5 m. Nota-se a cerca de } 60 \text { cm de } \\
\text { profundidade, camada mais densificada que no grupo B, mas aindalonge das condições de } \\
\text { impermeabilidade. }\end{array}$ \\
\hline Grupo D & $\begin{array}{l}\text { Solos argilosos (30- 40\% de argila total) e aindacom camada densificada a uns 50 cm de } \\
\text { profundidade. Ou solos arenosos como B, mascom camada argilosa quaseimpermeável, ou } \\
\text { horizonte de seixos rolados. }\end{array}$ \\
\hline
\end{tabular}
Fonte: MIGUEZ et al., 2016.

A classificação do uso e cobertura de solo foi feita de acordo com as semelhanças entre as características encontradas na área contribuinte e os atributos definidos pelo NRCS (2004) dispostos na tabela 2. Desta forma, os valores para CN variaram numa escala de 1 a 100 e retrataram as condições de cobertura do solo, desde uma cobertura muito impermeável até completamente permeável (TUCCI, 2012). O parâmetro CN foi calculado pela média ponderada entre os $\mathrm{CN}$ encontrados, de acordo com o tipo de solo e com o uso e cobertura do solo na bacia.

Tabela 2 - Valores de CN para bacias urbanas e suburbanas.

\begin{tabular}{|c|c|c|c|c|}
\hline $\begin{array}{l}\text { Descrição da Cobertura } \\
\text { Tipo de Cobertura e Condição Hidrológica }\end{array}$ & $\mathbf{A}$ & $\mathbf{B}$ & $\mathbf{C}$ & $\mathbf{D}$ \\
\hline \multicolumn{5}{|l|}{ Áreas urbanas desenvolvidas (vegetação existente) } \\
\hline \multicolumn{5}{|l|}{ Espaçoaberto (gramados, parques, campos de golfe, cemitérios, etc.) } \\
\hline $\begin{array}{l}\text { Condição deficiente (cobertura com grama }<50 \%) \\
\text { Condição regular (cobertura com grama } 50 \text { a } 75 \%) \\
\text { Condição boa (cobertura com grama }>75 \% \text { ) }\end{array}$ & $\begin{array}{l}68 \\
49 \\
39\end{array}$ & $\begin{array}{l}79 \\
69 \\
61\end{array}$ & $\begin{array}{l}86 \\
79 \\
74\end{array}$ & $\begin{array}{l}89 \\
84 \\
80\end{array}$ \\
\hline \multicolumn{5}{|l|}{ Áreas impermeáveis: } \\
\hline $\begin{array}{l}\text { Estacionamentos pavimentados, telhados, entrada para carros em moradias, } \\
\text { etc. (excluindo faixa de domínio) } \\
\text { Ruas e rodovias }\end{array}$ & 98 & 98 & 98 & 98 \\
\hline $\begin{array}{ccccccc}\text { Pavimentadas } \\
\text { (nãoincluindofaixa de } & \begin{array}{c}\text { comcalçadas, } \\
\text { domínio) }\end{array} & \text { guias } & \text { e } & \text { galeria } & \text { de } & \text { drenagem } \\
\end{array}$ & 98 & 98 & 98 & 98 \\
\hline
\end{tabular}




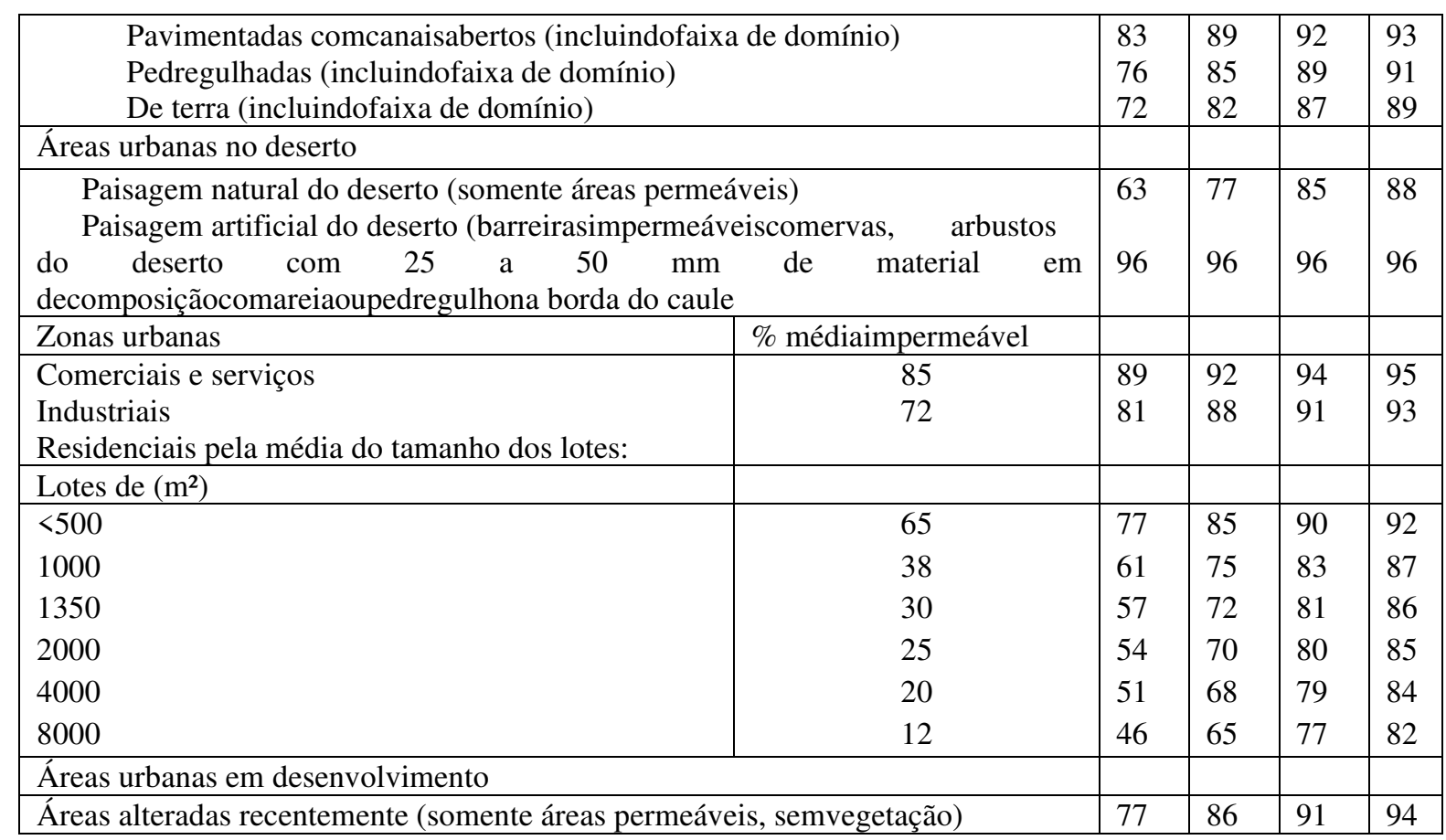

Fonte: NRCS, 2004.

Utilizado em métodos mais simplificados, o coeficiente de escoamento superficial, também conhecido como coeficiente runoff, é um parâmetro que representa as diferentes características do solo na bacia hidrográfica em estudo, sua aplicação visa separar a chuva efetiva da chuva total (MIGUEZ et al., 2016; TUCCI, 2012).

A partir da média ponderada entre as áreas contendo os diferentes usos de solo associados aos coeficientes encontrados na bacia urbana de estudo, a identificação dos valores relacionados aos fatores de uso do solo foi realizada com base na tabela 3 , seguindo a recomendação do SUDERHSA (2002).

Tabela 3 - Valores de Coeficiente de Escoamento (C) para algumas superfícies.

\begin{tabular}{|l|l|l|}
\hline Tipo de Superfície & Valor Recomendado & Faixa de Variação \\
\hline Concreto, asfalto e telhado & 0,95 & $0,90-0,95$ \\
\hline Paralelepípedo & 0,70 & $0,58-0,81$ \\
\hline Blockets & 0,78 & $0,70-0,89$ \\
\hline Concreto e asfalto poroso & 0,03 & $0,02-0,05$ \\
\hline Solo compactado & 0,66 & $0,59-0,79$ \\
\hline Matas, parques e campos de esporte & 0,10 & $0,05-0,20$ \\
\hline Grama solo arenoso & 0,10 & $0,08-0,18$ \\
\hline Grama solo argiloso & 0,20 & $0,15-0,30$ \\
\hline
\end{tabular}

Fonte: SUDERHSA, 2002. 


\section{RESULTADOS E DISCUSSÃO}

Os caminhos preferenciais do escoamento superficial gerados durante os eventos de precipitação ao longo da microbacia urbana de estudo podem ser visualizados na Figura 6. Quanto maior o número de ordem de afluência, mais linhas de fluxo confluem para tal direção, e o talvegue principal, definido com 634,74 m de comprimento, corresponde ao local onde há mais convergência de linhas de fluxo, ou seja, um percurso que apresenta grande potencial para receber volumes de água pluvial oriundos de diferentes localidades da BHASB e, portanto, possui maior tendência geradora de enchentes e alagamentos.

Nesta área de drenagem foram encontradas diferentes altitudes, variando entre 10,04 $\mathrm{m}$, na parte mais alta, e 3,58 m, nas proximidades do exutório (Figura 6). Sendo assim menores níveis foram observados na região central da bacia em relação às adjacências e, inclusive, a toda a área da BHASB situada à montante, resultando na convergência de fluxos para o local da avenida, ou seja, do ponto de vista topográfico, a região se comporta como um exutório de quase toda área da BHASB.

Figura 5 - Disposição dos cursos preferenciais de drenagem e talvegue da microbacia de estudo.

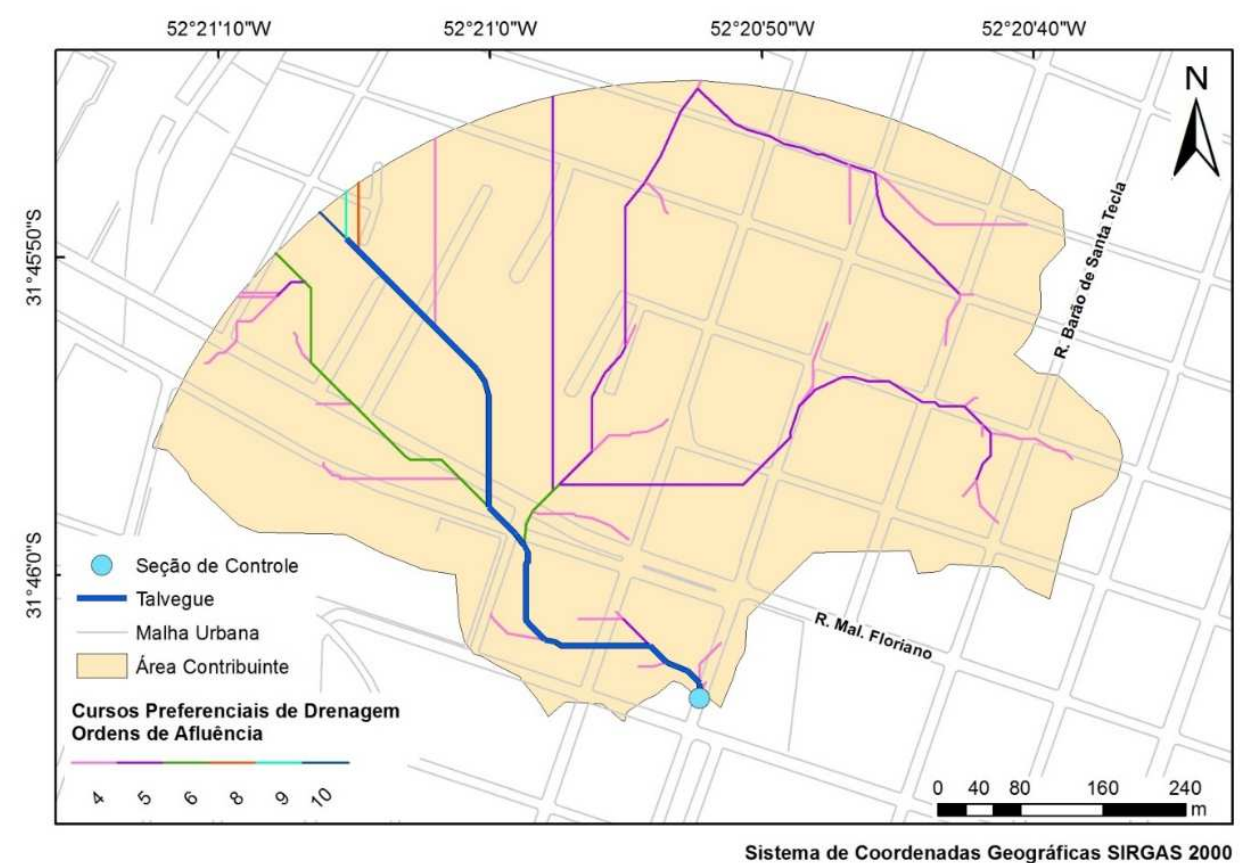


Figura 6 - Variação da altitude ao longo da microbacia urbana de estudo.

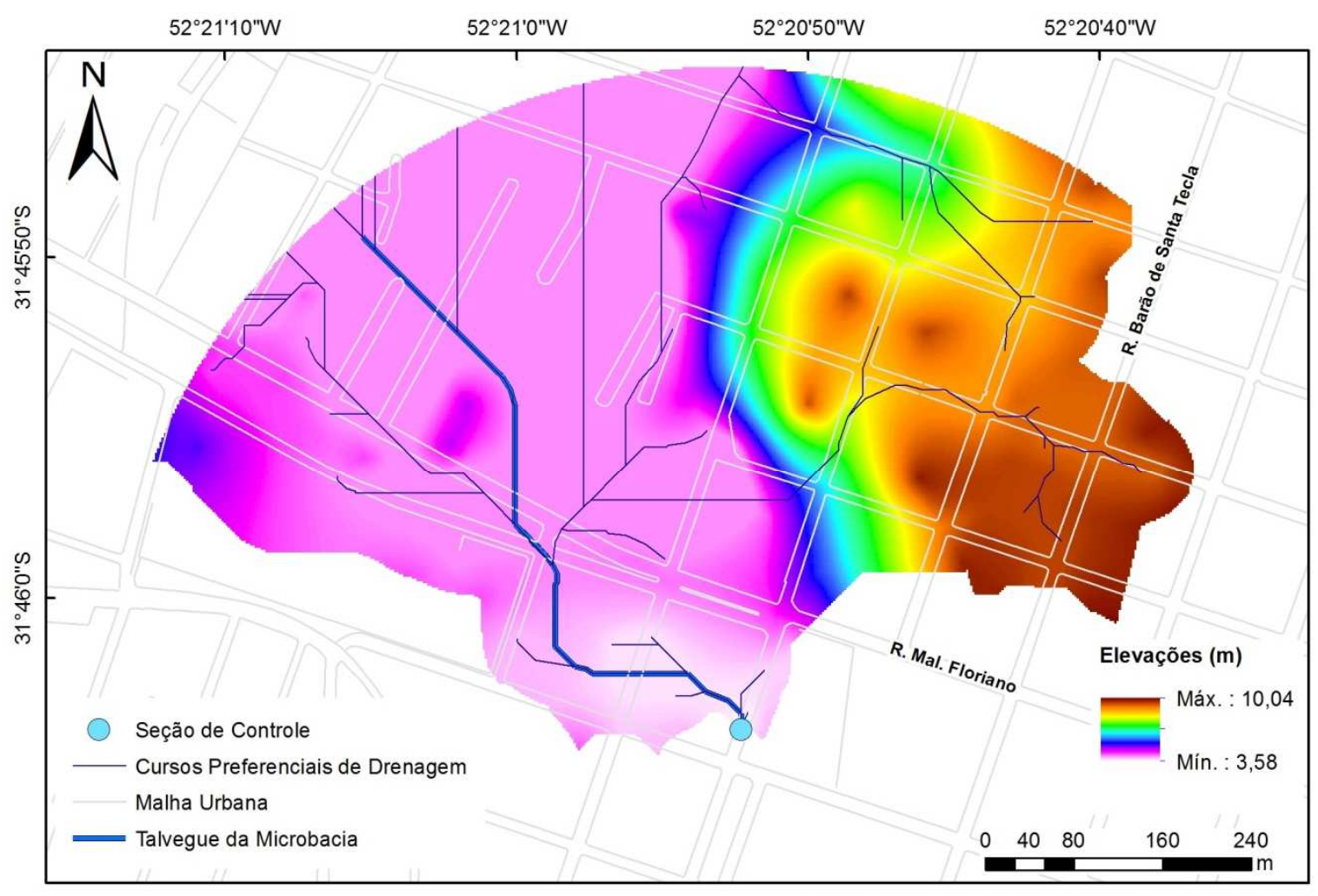

Sistema de Coordenadas Geográficas SIRGAS 2000

O valor de declividade média, obtido através das informações fornecidas sobre as propriedades do mapa de declividade (Figura 7), correspondeu a 1,138\%. Este índice de declividade apresentar valores relativamente altos, atingindo até $7 \%$ na região central da área analisada, algo que dificulta consideravelmente a infiltração das águas pluviais, uma vez que, em locais de terrenos mais íngremes, ocorre a diminuição das forças de contato entre a água precipitada e a superfície do solo, reduzindo a tendência de infiltração.

Em relação ao tipo de solo, foram encontradas duas classificações na área de estudo (Figura 8), na região central da microbacia foi identificado Espodossolo Humiluvico Hidromórfico (EKg) o qual possui acúmulo de matéria orgânica e alumínio no horizonte subsuperficial e apresenta forte restrição à drenagem. Nas parcelas laterais foi observada uma composição de três tipos de solo com predomínio de Planossolo Háplico Eutrofico (Sxe), caracterizado pela mudança abrupta entre o horizonte superficial e o sub-superficial, possui considerável adensamento, principalmente na camada sub-superficial, dificultando a penetração de raízes e também a percolação da água (ALMEIDA et al., 2019; IBGE, 2007). 
Figura 7 - Distribuição dos índices de declividade ao longo da bacia hidrográfica de estudo.

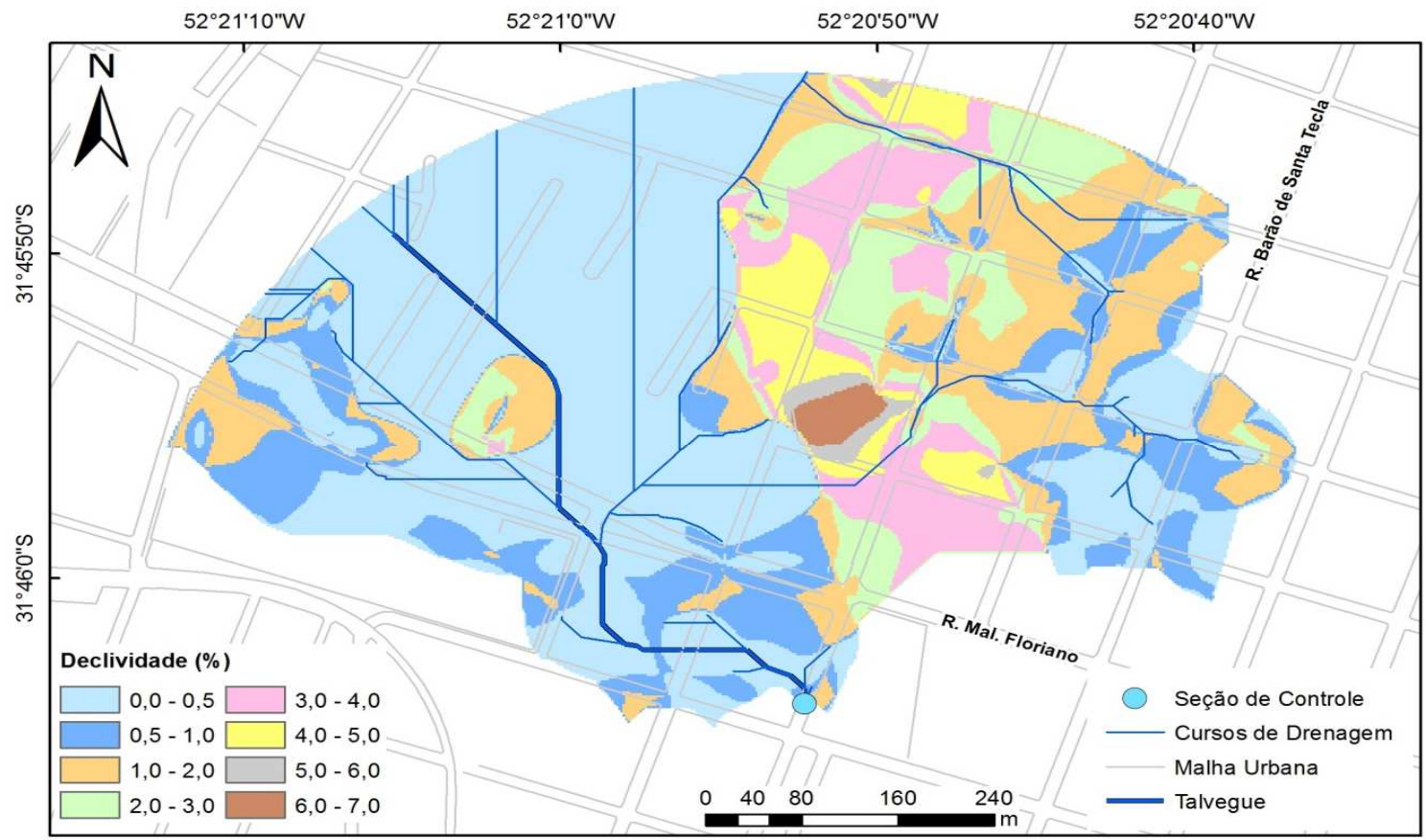

Sistema de Coordenadas Geográficas SIRGAS 2000

Figura 8 - Tipos de solo encontrados área de estudo.

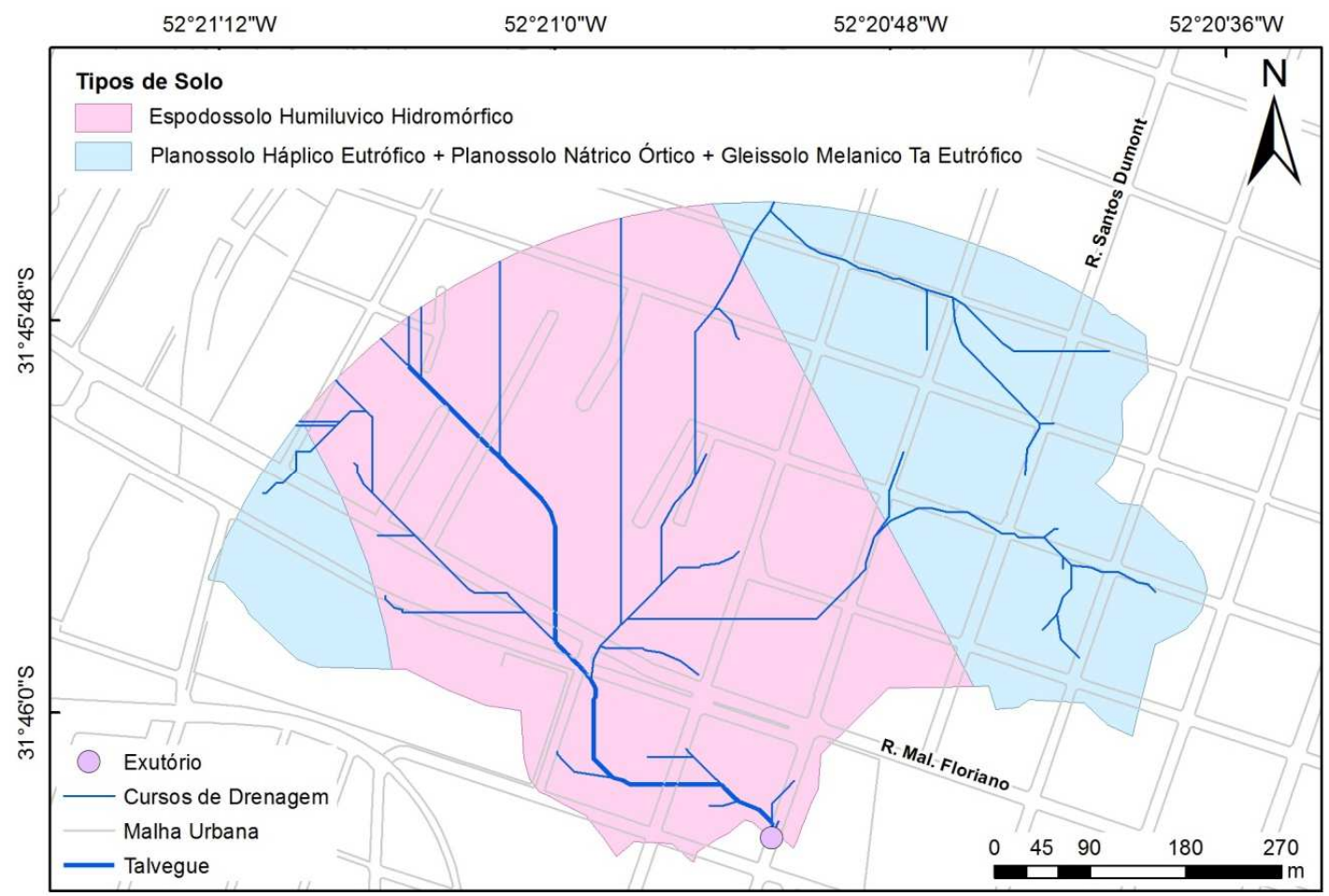

Sistema de Coordenadas Geográficas SIRGAS 2000 
$\mathrm{Na}$ análise do mapa da cobertura e uso do solo (Figura 9), foram observados quatro tipos de cobertura: vegetação, constituindo $26,3 \%$ da área total da bacia; telhado, 38,19\%; asfalto, 21,20\%, e; solo exposto, 14,34\%. Estes índices indicam grande parcela impermeabilizada da bacia, quase $60 \%$ da área total, onde a infiltração é considerada desprezível ou nula. A vegetação, por sua vez, não chega a representar 30\%, e o restante, cerca de $14 \%$, é composto por solo exposto, o qual também não contribui significativamente para infiltração das águas de deflúvio. Sendo assim, este é mais um fator que contribui para a geração de escoamento superficial na localidade.

Em relação às condições de drenagem na bacia, para definição do índice $\mathrm{CN}$, foi necessário associar os tipos de solo encontrados na bacia aos grupos hidrológicos do método SCS (Tabela 1). O solo EKg foi classificado como pertencente ao grupo hidrológico B, um solo com alta restrição à drenagem por ser hidromórfico, e que apresenta textura arenosa predominante e, o solo Sxe teve suas características associadas ao grupo hidrológico D, por apresentar horizonte B adensado e geralmente com acentuada concentração de argila, sendo imediatamente subjacente à camada superficial, com permeabilidade lenta ou muito lenta, sendo imperfeitamente ou mal drenado (ALMEIDA et al., 2019; IBGE, 2007).

Figura 9 - Uso e cobertura área do solo da contribuinte analisada.

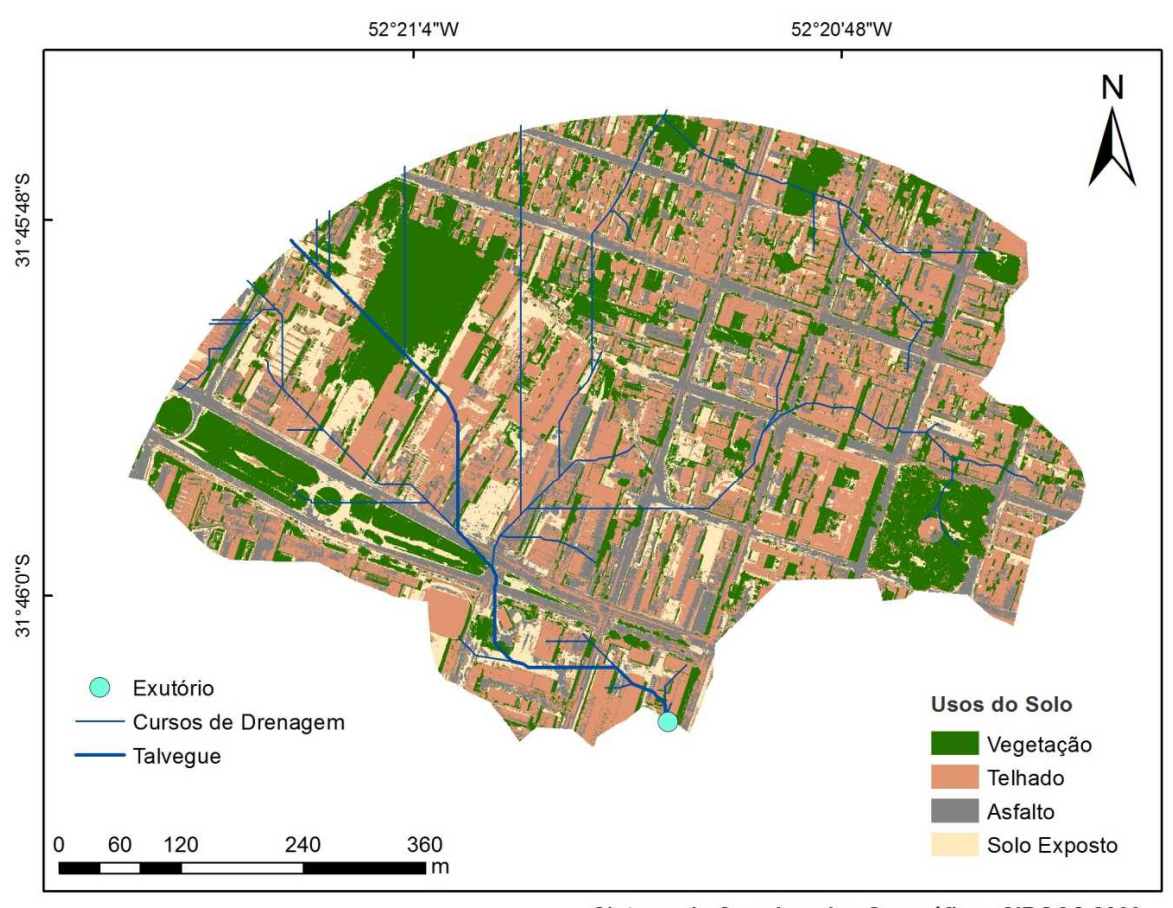

Sistema de Coordenadas Geográficas SIRGAS 2000 
Os valores de $\mathrm{CN}$ distribuídos ao longo da bacia contribuinte estão dispostos na tabela 4, o resultado foi um $\mathrm{CN}$ médio igual a 92,14, cujo valor pode ser considerado altíssimo numa escala que parte do 1, para superfícies completamente permeáveis, até 100, quando a cobertura é muito impermeável (TUCCI, 2012), evidenciando a forte influência da impermeabilização da superfície provocada pela urbanização.

$\mathrm{Na}$ determinação do coeficiente de escoamento superficial médio da bacia, diferentes índices $\mathrm{C}$ foram associados às áreas expostas na tabela 5. Desta forma, o coeficiente runoff $(\mathrm{C}$ médio) na área analisada resultou em 0,685 , um valor alto para sua escala de aplicação, que varia de 0,02 até 0,95 (SUDERHSA, 2002), indicando, também, uma maior tendência à impermeabilização nas parcelas da bacia de estudo.

Tabela 4 - Obtenção do valor de CN a partir da distribuição do uso e cobertura do solo na bacia

\begin{tabular}{|c|c|c|c|c|c|c|}
\hline Cobertura & Solo & Área $\left(m^{2}\right)$ & $\begin{array}{l}\text { Grupo } \\
\text { de Solo }\end{array}$ & $\mathbf{C N}$ & $\begin{array}{l}\text { Classificação conforme NRCS } \\
(2004)\end{array}$ & Área * CN \\
\hline \multirow[t]{2}{*}{ Vegetação } & Sxe & 44302,83 & $\mathrm{D}$ & 89 & \multirow{2}{*}{ 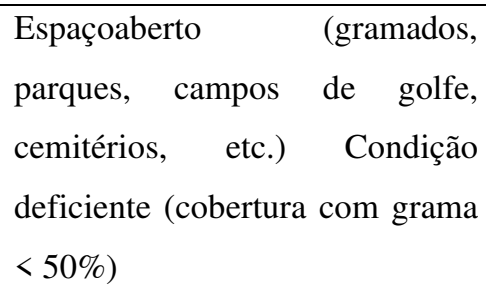 } & 3942951,73 \\
\hline & Ekg & 66619,92 & B & 79 & & 5840616,58 \\
\hline \multirow[t]{3}{*}{ Telhado } & Sxe & 59598,13 & $\mathrm{D}$ & 98 & \multirow{3}{*}{$\begin{array}{l}\text { Áreas impermeáveis: } \\
\text { Estacionamentos pavimentados, } \\
\text { telhados, entrada para carros em } \\
\text { moradias, etc. (excluindofaixa de } \\
\text { domínio) }\end{array}$} & 1393301,05 \\
\hline & Ekg & 92924,12 & B & 98 & & 4590619,38 \\
\hline & & & & & & \\
\hline \multirow{2}{*}{$\begin{array}{l}\text { Solo } \\
\text { Exposto }\end{array}$} & Sxe & 15655,07 & $\mathrm{D}$ & 89 & \multirow{2}{*}{$\begin{array}{l}\text { Ruas e rodovias de terra } \\
\text { (incluindofaixa de domínio) }\end{array}$} & 5262973,69 \\
\hline & Ekg & 41706,59 & B & 82 & & 9106563,39 \\
\hline \multirow[t]{2}{*}{ Asfalto } & Sxe & 46843,05 & $\mathrm{D}$ & 98 & \multirow{2}{*}{$\begin{array}{l}\text { Ruas e rodovias pavimentadas } \\
\text { comcalçadas, guias e galeria de } \\
\text { drenagem (nãoincluindofaixa de } \\
\text { domínio) }\end{array}$} & 3419940,72 \\
\hline & Ekg & 53978,29 & $\mathrm{~B}$ & 98 & & 5289872,33 \\
\hline
\end{tabular}


Tabela 5 - Obtenção do valor de C a partir da distribuição do uso e cobertura do solo na bacia

\begin{tabular}{|l|r|l|c|r|}
\hline Cobertura & Área $\left(\mathbf{m}^{\mathbf{2}} \mathbf{)}\right.$ & $\begin{array}{l}\text { Tipo de Superfície conforme SUDERHSA, } \\
\mathbf{2 0 0 2}\end{array}$ & Coeficiente C & C * Área \\
\hline Telhado & 143214,78 & Concreto, asfalto e telhado & 0,95 & 136054,05 \\
\hline Asfalto & 79497,42 & Concreto, asfalto e telhado & 0,95 & 75522,54 \\
\hline Solo Exposto & 53772,71 & Solo compactado & 0,66 & 35489,99 \\
\hline Vegetação & 98523,22 & Matas, parques e campos de esporte & 0,10 & 9852,32 \\
\hline
\end{tabular}

Todos os fatores evidenciados acima influenciam negativamente na microdrenagem da Av. Saldanha Marinho e atuam ao mesmo tempo em situações de chuvas intensas, desencadeando alagamentos na região, com muita facilidade (Figura 10).

Na prática, existem outros fatores que influenciam na drenagem local, e em ambientes urbanos de forma geral, como, por exemplo, a disposição inadequada de resíduos sólidos, os quais são carreados pelas águas pluviais, durante os eventos chuvosos, e acabam entupindo as bocas de lobo e reduzindo a eficiência da microdrenagem, podendo também danificar o sistema.

Figura 10: Avenida Saldanha Marinho, 2015. Fonte: Adaptado de Oliveira (2017).

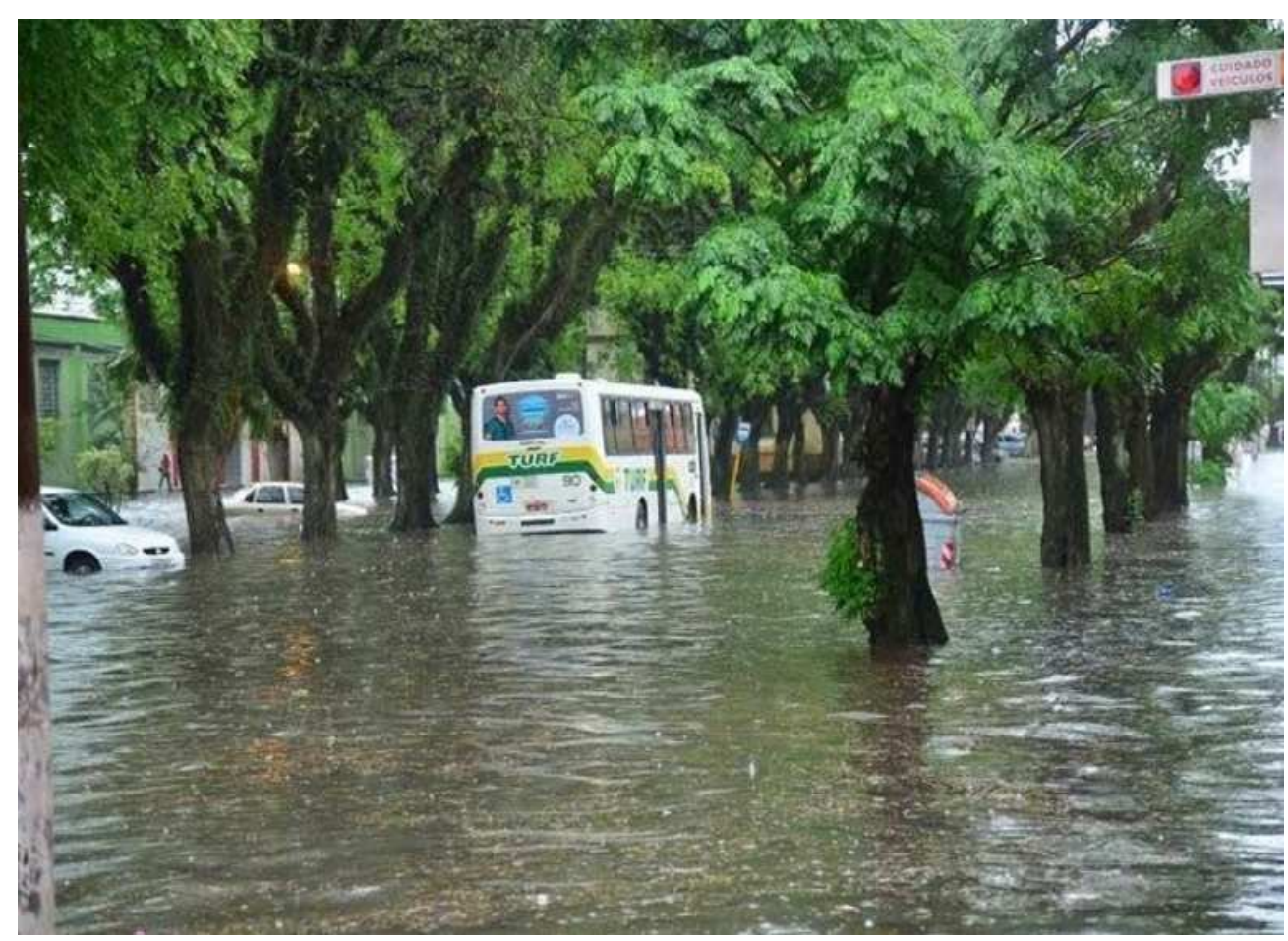


Desta forma, em relação aos aspectos observados na microbacia, suas características demonstram um grande potencial gerador de escoamento superficial, que contribui consideravelmente para os alagamentos na localidade. Tal afirmação, também pode ser observada no estudo de Peruzzo (2017), onde três simulações diferentes no software HEC$R A S$ indicaram regiões inundáveis ao longo da BHASB, sendo uma delas a localidade da Avenida Saldanha Marinho, local do antigo leito do Arroio Santa Bárbara.

As soluções de drenagem urbana devem estar inseridas em um plano diretor de drenagem, que por sua vez, deve constituir o plano diretor do município (TUCCI, 2003). Em Pelotas, o Plano Diretor (PELOTAS, 2019) prevê adequações na rede de drenagem nas imediações do IFSul, região que contempla parte da área analisada. Uma proposta para a solução dos frequentes alagamentos pode ser o redimensionamento e execução da manutenção das galerias subterrâneas locais, ou implantar técnicas de redução de enchentes, por meio de medidas de controle na fonte (HANSMANN, 2013) como telhados verdes, poços de infiltração, dentre outros (BAPTISTA et al., 2005), ou até, visando uma medida de controle centralizado, instalar uma bacia de detenção sob o estacionamento do centro de comércio popular (Pop Center), no intuito deassociar dispositivos de drenagem urbana e áreas de serventia para população. Para esta última alternativa, os dados sintetizados na tabela 6 podem ser aplicados em posterior dimensionamento hidráulico e hidrológico.

Tabela 6 - Resumo das características da área de estudo.

\begin{tabular}{|l|l|}
\hline Área da bacia (ha) & 37,501 \\
\hline Declividade média (\%) & 1,138 \\
\hline Comprimento do talvegue (m) & 634,737 \\
\hline CN médio & 92,135 \\
\hline C médio & 0,685 \\
\hline
\end{tabular}

Na hipótese de implantação da estrutura de detenção, no entanto, em vista das baixas altitudes na região e, em eventos de precipitação, da proximidade da superfície com o nível freático, haveria necessidade do dispositivo ser constituído de concreto impermeável, algo que tornaria mais alto o custo da obra e, também, após a construção, seria necessária a realização de limpezas com determinada frequência ou instalação de estruturas de pré-tratamento, a fim de evitar o assoreamento da bacia (BAPTISTA et al., 2005; SUDERHSA, 2002).Porém, haveria a vantagem em relação à possibilidade de reúso da água pluvial armazenada no 
dispositivo, mas esta alternativa demanda pesquisas à parte, devido às águas pluviais serem portadoras de toxinas e compostos orgânicos.

\section{CONCLUSÃO}

A partir deste estudo foi possível concluir que o fato da Avenida Saldanha Marinho apresenta intensos e frequentes alagamentos não é por acaso, muitos fatores atuam ao mesmo tempo durante os eventos de precipitação e, todos os analisados, contribuem para a má drenagem local.

O acúmulo de águas residuárias no meio urbano também apresenta aspectos preocupantes do ponto de vista sanitário, devido à má disposição de resíduos sólidos e a presença de esgoto cloacal na rede de drenagem em alguns pontos da cidade (DALTOÉ et al., 2016), em situações de fortes chuvas, propiciam o contato direto da população com a água contaminada, desencadeando a proliferação de doenças.

Para a situação observada, portanto, é necessário analisar quais soluções de drenagem apresentam maior viabilidade, tanto de implantação, como de operação e eficiência.

A implantação de uma bacia de detenção, proposta neste estudo, precisa ser avaliada, primeiramente, do ponto de vista hidrológico e hidráulico e existem, também, outras soluções, como as medidas de controle na fonte, as quais podem ser implantadas por meio de técnicas de reuso, áreas verdes, dentre outros, ocasionando a diminuição das águas de deflúvio e, consequentemente, a redução dos alagamentos em Pelotas e nas diversas regiões urbanas de forma geral, diminuindo também o contato dos cidadãos com as águas residuárias e a possibilidade de sofrerem com doenças de veiculação hídrica, tornando os ambientes urbanos mais saudáveis e com maior qualidade de vida à população.

\section{REFERENCIAS}

ALMEIDA, E. de P.; ZARONI, M. J.; SANTOS, H. G. dos. Espodossolos Humilúvicos. AGEITEC. Agência Embrapa de Informação Tecnológica.

ALMEIDA, E. de P.; ZARONI, M. J.; SANTOS, H. G. dos. PlanossolosHáplicos. AGEITEC. Agência Embrapa de Informação Tecnológica. Disponível em: <http://twixar.me/myRT>. Acesso em: Jun. 2019. 
BAPTISTA, M.; NASCIMENTO, N.; BARRAUD, S. Técnicas Compensatórias em Drenagem Urbana. Porto Alegre: ABRH, 2005. 266 p.

CANHOLI, A. P. Drenagem Urbana e Controle de Enchentes. São Paulo: Oficina de Textos, 2005. 302 p.

CASACA, J. M.; MATOS, J. L. de; DIAS, J. M. B. Topografia Geral. Tradução Luiz Felipe Coutinho Ferreira da Silva, Douglas Corbari Corrêa. 4.ed. Reimpr. Rio de Janeiro, LTC: 2013. 208 p.

CUNHA, N.G da; SILVEIRA, R.J.C.S; SEVERO, C.R.S. Solos e Terras do Planalto SulRio-Grandense e Planícies Costeiras. Pelotas: Embrapa Clima Temperado. 44p. ISSN 15168832. 2006.

DAlTOÉ, M. F; CASTRO, A. S; CORRÊA, L. B; LEANDRO, D; BARCELOS, A. A. Resíduos Sólidos na Rede de Microdrenagem: Uma Análise Qualitativa da Cidade de Pelotas - RS. REMOA/UFSM, v. 15, n. 1, jan. - abr., 2016.

HANSMANN, H. Z. Descrição e Caracterização das Principais Enchentes e Alagamentos de Pelotas - RS. 2013. 63f. Trabalho de Conclusão de Curso (Graduação em Engenharia Ambiental e Sanitária) - Centro de Engenharias, Universidade Federal de Pelotas, Pelotas RS. 2013.

IBGE. Manual Técnico de Pedologia. 2.ed. Rio de Janeiro: Ministério do Planejamento, Orçamento e Gestão. Instituto Brasileiro de Geografia e Estatística - IBGE.Diretoria de Geociências. Coordenação de Recursos Naturais e Estudos Ambientais.Manuais Técnicos em Geociências. n. 4. 2007. 316 p.

McCORMAC, J. C. Topografia. Tradução Daniel Carneiro da Silva; revisão técnica Daniel Rodrigues dos Santos, Douglas Corbari Corrêa, Felipe Coutinho Ferreira da Silva. 5.ed. Reimpr. Rio de Janeiro, LTC: 2013. 391 p.

MIGUEZ, M.; VERÓL, A. P.; REZENDE, O. M. Drenagem Urbana: Do projeto tradicional à sustentabilidade. 1.ed. Rio de Janeiro: Elsevier, 2016.

OLIVEIRA, M. C. A transposição do leito do canal Santa Bárbara, Pelotas/RS: utilização de SIG na análise temporal de uma alteração de drenagem urbana. 2017. 62f. Trabalho de Conclusão de Curso (Graduação em Engenharia Ambiental e Sanitária) - Centro de Engenharias, Universidade Federal de Pelotas, Pelotas-RS. 2017.

PELOTAS. Prefeitura Municipal de Pelotas. Lei $\mathbf{N}^{\mathbf{0}}$ 5502, de 11 de setembro de 2008. Institui o Plano Diretor Municipal e estabelece as diretrizes e proposições de ordenamento e desenvolvimento territorial no município de Pelotas, e dá outras providências. $59 \mathrm{p}$. Disponível em: <http://leismunicipa.is/gicsd>. Acesso em: Jul. 2019. 
PELOTAS. Prefeitura Municipal de Pelotas. Lei $\mathbf{N}^{\mathbf{0}}$ 6636, de 03 de outubro de 2018. Altera a Lei Municipal n 5.502 de 11 de se- tembro de 2008, que dispõe sobre o Plano Diretor de Pelotas, e dá outras providências. 32 p. Disponível em: <http://leismunicipa.is/wircd>. Acesso em: Nov. 2019.

PELOTAS. Prefeitura Municipal de Pelotas. Ortofoto. Captura em 2015. Fornecida em 2016.

PERUZZO, A. S. Proposta metodológica para simulação de inundações na Bacia do Santa Bárbara. 2017. 84f. Trabalho de Conclusão de Curso (Graduação em Engenharia Ambiental e Sanitária) - Centro de Engenharias, Universidade Federal de Pelotas, Pelotas-RS. 2017.

PETER, G. D. Santa Bárbara: o braço morto do arroio que ainda vive na memória. 2004. 32f. Monografia (especialização em Conservação de Patrimônio em Centros Urbanos). Porto Alegre: Faculdade de Arquitetura e Urbanismo, Universidade Federal do Rio Grande do Sul, Porto Alegre - RS, 2004.

SANEP. Pontos Cotados da Zona Urbana da Cidade de Pelotas. Documento em formato DWG. 2017.

SANEP. Sistema Autônomo de Saneamento de Pelotas. Avaliação da Segurança da Barragem Santa Bárbara. Pelotas, 2008. 260 p.

SOARES, P. R. R. Del proyecto urbano a la producción del espacio: morfología urbana de la ciudad de Pelotas, Brasil (1812-2000). 2002. 507f. Tese (Doutorado em Geografia Humana).Barcelona: Facultad de Geografía e Historia, Universidad de Barcelona, Barcelona ES, 2002.

\section{SUDERHSA, CH2M HILL DO BRASIL. Manual de Drenagem Urbana: Região}

Metropolitana de Curitiba-PR. Governo do Estado do Paraná. SUDERHSA -

Superintendência de Desenvolvimento de Recursos Hídricos e Saneamento Ambiental. v.1.

Não publicado. 2002. 150 p.

TUCCI, C. E. M. Gerenciamento da drenagem Urbana. Revista Brasileira de Recursos Hídricos. Porto Alegre, v.7, n.1, p.5-27, 2001. Disponível em: 〈http://twixar.me/6bBT>. Acesso em: Nov. 2019.

TUCCI, C. E. M. Hidrologia: ciência e aplicação. 4. ed. Porto Alegre: UFRGS/ABRH, 2012. 943 p.Disponível em: 〈http://twixar.me/TyRT>. Acesso em: Jun. 2019. 